\title{
Policy and program implications of the Matching Grants Program in the Philippines
}

Marilou Palabrica-Costello

Nimfa Ogena

Alejandro N. Herrin

Follow this and additional works at: https://knowledgecommons.popcouncil.org/departments_sbsr-rh

Part of the Demography, Population, and Ecology Commons, International Public Health Commons, Maternal and Child Health Commons, Public Health Education and Promotion Commons, and the Women's Health Commons

How does access to this work benefit you? Let us know!

\section{Recommended Citation}

Palabrica-Costello, Marilou, Nimfa Ogena, and Alejandro N. Herrin. 2003. "Policy and program implications of the Matching Grants Program in the Philippines," FRONTIERS Final Report. Washington, DC: Population Council. 
Policy and Program Implications of the Matching Grants Program in the Philippines

\section{Marilou Palabrica-Costello Nimfa Ogena Alejandro N. Herrin}

March 2003

The Matching Grants Program (MGP) was funded by the United States Agency for International Development (USAID) under the terms of Cooperative Agreement Number HRN-A-00-98-00012-00 and Population Council Project Number 5807.13017.455. The opinions expressed herein are those of the authors and do not necessarily reflect the views of USAID. 


\begin{tabular}{|c|c|}
\hline ANE OR/TA & Asia and the Near East Operations Research/Technical Assistance \\
\hline BHS & Barangay Health Station \\
\hline BHW & Barangay Health Worker \\
\hline BNS & Barangay Nutrition Scholar \\
\hline BSPO & Barangay Supply Point Officer \\
\hline BTL & Bilateral Tubal Ligation \\
\hline CBMIS & Community-based Management and Information System \\
\hline CBMO & Community-based Managed and Owned Information System \\
\hline $\mathrm{CHO}$ & City Health Office \\
\hline CPR & Contraceptive Prevalence Rate \\
\hline DMPA & Depo Medroxy-Progesterone Acetate \\
\hline $\mathrm{DOH}$ & Department of Health \\
\hline EPI & Expanded Program on Immunization \\
\hline FIC & Fully Immunized Children \\
\hline FIM & Fully Immunized Mother \\
\hline FHSIS & Field Health Surveillance and Information System \\
\hline FP & Family Planning \\
\hline IEC & Information, Extension and Communication \\
\hline IUD & Intra Uterine Device \\
\hline LGU & Local Government Unit \\
\hline LPP & Local Government Performance Project \\
\hline $\mathrm{MCH}$ & Maternal and Child Health \\
\hline MGP & Matching Grants Program \\
\hline $\mathrm{MHC}$ & Main Health Center \\
\hline MHO & Municipal Health Office \\
\hline MOA & Memorandum of Agreement \\
\hline MSH & Management Sciences for Health \\
\hline MWRA & Married Women of Reproductive Age \\
\hline NDHS & National Demographic and Health Survey \\
\hline NFP & Natural Family Planning \\
\hline NGO & Nongovernmental Organization \\
\hline NTP & National Tuberculosis Program \\
\hline $\mathrm{PHO}$ & Provincial Health Office \\
\hline $\mathrm{PMC}$ & Pre-marital Counseling \\
\hline RHU & Rural Health Unit \\
\hline RTA & Regional Technical Assistant \\
\hline TBA & Traditional Birth Attendant \\
\hline $\mathrm{TT}$ & Tetanus Toxoid \\
\hline TT2+ & Tetanus Toxoid Two Plus \\
\hline USAID & U.S. Agency for International Development \\
\hline $\mathrm{VAC}$ & Vitamin A Supplementation Coverage \\
\hline VSS & Voluntary Surgical Sterilization \\
\hline WRA & Women of Reproductive Age \\
\hline
\end{tabular}

Policy and Program Implications of the Matching Grants Program in the Philippines 


\section{Introduction}

In 1999, the Department of Health, with support from USAID and technical assistance from Management Sciences for Health (MSH), implemented the Matching Grants Program (MGP) as a component of the Local Government Performance Program (LPP). The MGP aims to improve the capability of municipalities and component cities to expand service delivery, and to achieve significant increases in rates of fully immunized children (FIC), vitamin A supplementation (VAC), tetanus toxoid immunization for women (TT2+), as well as in the use of family planning methods (CPR), especially modern methods.

As an approach to expanding service coverage, the MGP was developed with the following features: (1) it targets mid-size municipalities and component cities, initially those with a population of 100,000 and above, where primary health care services are provided; (2) it employs a "grantee-friendly" application process, with the Local Government Unit (LGU) determining its own goals and program direction; (3) it provides flexible funding of up to P500,000 ${ }^{1}$ and access to technical assistance; and (4) it encourages LGUs to increase fund allocation and expenditures for MGP-assisted programs through a "match" or counterpart funding.

Cities had to meet established criteria in order to be selected to participate in the MGP program, including: (1) clearly defined funding match, activities and budget; (2) activities designed to increase service utilization among target clientele; (3) activities that will result in direct increases in coverage; and (4) discrete activities with a reasonable chance of obtaining measurable impacts within 12 months or less.

\section{MGP Evaluation Study}

Upon the request of the USAID Mission, the Frontiers in Reproductive Health Program worked closely with Management Sciences for Health to conduct an evaluation of the MGP during 1999-2000. This activity falls under USAID's IR 1: Testing innovative solutions to service delivery problems, supportive of USAID's Strategic Objective 3: Improving Maternal and Child Health.

Two types of evaluations were carried out: performance and impact. Program performance was measured (using the "input-process-output-outcome" framework) through careful monitoring of MGP inputs, processes, and outputs using program-based data. Outcomes were evaluated using population-based data in a before-after comparison group design.

The performance evaluation was conducted in four MGP areas, namely: San Jose del Monte, Bulacan; Dasmarinas, Cavite; Tacloban City, Leyte; and Digos, Davao del Sur. The impact evaluation was conducted in Taytay, Rizal with Binongonan, Rizal serving as the comparison group, and in San Carlos, Negros Occidental, with Cadiz, Negros

\footnotetext{
${ }^{1}$ The average funding provided to LGUs was about P375,000 or approximately US\$10,000. Policy and Program Implications of the Matching Grants Program in the Philippines
} 
Occidental serving as the comparison group. The results of these two sets of evaluations are described in separate reports. ${ }^{2}$

The purpose of this report is to briefly summarize the results of the evaluations as a springboard for discussing program and policy issues. Specifically, this analysis attempts to draw out the program and policy implications of the findings from the MGP process and impact evaluations. There are two types of lessons to be learned. One is useful to local government authorities and involves lessons for planning and implementing local health interventions that are effective and have large impacts. The second is useful for Department of Health authorities and other policy stakeholders and involves lessons for formulating policies and programs to support local governments in expanding health service coverage in the context of overall health sector reform.

\section{A. Major Findings from the Process (Performance) Evaluation}

The process evaluation has uncovered a number of interesting findings with respect to the planning and implementation of interventions designed to expand services and increase coverage in the fours areas of concern: fully immunized children (FIC), vitamin A coverage (VAC), tetanus toxoid immunization (TT2+), and contraceptive prevalence rate (CPR).

LGU Capacity for Planning Focused Interventions. With technical assistance from Department of Health and Management Sciences for Health personnel, local government units (LGUs) were able to identify specific demand and service delivery problems in the four program areas, and designed focused interventions to address these problems. For the most part, the LGUs relied on data from the Field Health Surveillance and Information System (FHSIS), the only data available at that time, in analyzing health problems and setting targets. The limitations of FHSIS data for estimating coverage rates of interventions are well known, but these were useful as a starting point. Based on their assessment of services needing significant expansion or improvement, the LGUs chose corresponding interventions. The types of interventions chosen by each MGP participant varied, both in terms of service areas emphasized and specific types of activities to address unmet needs and provide measurable impacts. The activities are shown in Table 1 below.

\footnotetext{
${ }^{2}$ See Appendix I and II.

Policy and Program Implications of the Matching Grants Program in the Philippines 
Table 1: MGP Interventions in the Four MGP Evaluation Areas, February 2000

\begin{tabular}{|c|c|c|c|c|}
\hline MGP Activities & $\begin{array}{l}\text { San } \\
\text { Jose Del } \\
\text { Monte }\end{array}$ & Dasmarinas & Tacloban & Digos \\
\hline CBMIS Implementation & $\mathrm{X}$ & $\mathrm{X}$ & $\mathrm{X}$ & \\
\hline CBMO & & & & $\mathrm{X}$ \\
\hline $\begin{array}{l}\text { Outreach activities (clinic based, community- } \\
\text { based, or at work-site) }\end{array}$ & $\mathrm{X}$ & $\mathrm{X}$ & $\mathrm{X}$ & $\mathrm{X}$ \\
\hline $\begin{array}{l}\text { "Mop-up activities" (home-based follow-up } \\
\text { services for missed clients) }\end{array}$ & $\mathrm{X}$ & $\mathrm{X}$ & $\mathrm{X}$ & $X$ \\
\hline Family planning referrals (IUD and/or VSS) & $\mathrm{X}$ & $\mathrm{X}$ & $X$ & $X$ \\
\hline Provision of IUDs to local health workers & & $X$ & & \\
\hline Training on IUD Insertion and Removal & $\mathrm{X}$ & & & \\
\hline $\mathrm{TT} 2+$ referrals & & $X$ & & \\
\hline $\mathrm{TT} 2+$ in pre-marriage counseling & & & $\mathrm{X}$ & $\mathrm{X}$ \\
\hline $\begin{array}{l}\text { Training of TBAs on aseptic techniques and } \\
\text { referrals for TT and FP }\end{array}$ & & $\mathrm{X}$ & & \\
\hline Health and nutritional post & & & & $\mathrm{X}$ \\
\hline Partnership with NGOs in service provision & & & $\mathrm{X}$ & \\
\hline
\end{tabular}

Source: Costello, Manganar and Mosende (2001: Table 6)

In some cases, the interventions were creative and innovative. For example, Dasmarinas adopted a three-pronged approach to improve TT2+ coverage. These are the Barangay Health Station Expanded Program of Immunization Team approach, home visits to follow-up defaulters, and industrial site visits to provide services to a working and highly mobile population of women. Tacloban, on the other hand, added family planning and TT2+ services to its existing social hygiene clinic and pre-marital counseling services. It also tapped NGOs to expand its service delivery network. Digos also added TT2+ services to its pre-marriage counseling program.

Innovation in Information System in Support of Service Delivery. One major innovation is the application of a new health information technology - the Community-Based Monitoring and Information System (CBMIS). The CBMIS use as a mechanism to identify women in need of family planning services was first introduced by MSH in Pangasinan and Iloilo Cities. FRONTIERS Manila provided technical assistance in 
sharpening the CBMIS to be able to address women's unmet needs for spacing and limiting births (including the needs of dissatisfied users drawing from experience in Davao and Pangasinan). The CBMIS, as it has evolved under the MGP, combines information gathering with service delivery. It provides information on clients with unmet needs under the four major health programs (family planning, vitamin A supplementation, FIC and TT2+). These needs were determined during house-to-house visits in the catchment areas by barangay health workers (BHWs). In San Juan Del Monte, Bulacan, an incentive system attracted volunteers to sustain the CBMIS. There they used the CBMIS, together with the call slip system, to give the rural health unit a system for prioritizing service provision. CBMIS information was also presented on a Data Health Board for community use.

Mobilization of New Resources for Health. The MGP funds represented an additional source of funding for health services. The process evaluation found that LGUs were able to generate additional resources, whether financial or in-kind, from cooperating institutions such as the Department of Health and NGOs. For example, to implement Family Health Days in Tacloban, logistical support, medicines and supplies from the Department of Health, the provincial health office, and the GLAXO drug company augmented the local government unit's resources. Active involvement of barangay health workers, service point officers, nutrition scholars and the facilitative efforts of local barangay officials were crucial in community mobilization. NGOs (LEFADO and Marie Stopes Foundation), the city population office, and the Leyte Institute of Technology provided strong partnership in advocacy and service provision.

Outputs and Coverage. Based on program statistics, the performance of the four Matching Grants Program study areas, with respect to outputs, varied by specific intervention. The CBMIS did, in fact, enable workers to reach quite a number of households by identifying eligible populations requiring services. A large proportion of those identified did seek out the needed services, either through outreach activities or through the routine services offered in the study area. The three-pronged approach to TT2+ implemented in Dasmarinas identified and served a number of women eligible for TT2+ injections.

However, based on service statistics (FHSIS), overall performance in the four study areas with respect to improving coverage is mixed. In San Jose del Monte. FIC, VAC and TT2+ coverage have been maintained at their previous levels, and CPR doubled compared to the baseline. In Dasmarinas, while performance in one rural health unit improved dramatically for TT2+, there were large reductions in FIC and VAC coverage. In Tacloban City, Leyte, initial data show some progress in increasing TT2+ coverage based on identified targets (89\%). In Digos, Davao del Sur, with only a six-month observation period, TT2 + coverage increased somewhat, but CPR, FIC and VAC coverage fell modestly. These results are based on service statistics (FHSIS) that may not be accurate and may not be comparable between different periods given variable reporting coverage rates and irregular logistics support. Hence, conclusions about impacts should be interpreted with caution. A comparable set of data before and after the intervention based on a survey of the eligible population is needed to determine changes

Policy and Program Implications of the Matching Grants Program in the Philippines 
in actual coverage due to the interventions. This type of data can be found in the impact evaluation described below.

\section{B. Major Findings from the Impact Evaluation}

For the impact evaluation, two Matching Grants Program areas and their corresponding comparison sites were studied. The experiment areas were Taytay, Rizal and San Carlos City, Negros Occidental and their respective comparison areas were Binongonan, Rizal and Cadiz, Negros Occidental. The experiment and comparison sites were matched according to the following characteristics: both local government units were required to be from the same province to control for administrative and other forms of support provided at the province level; similar population sizes; same income class; and similar performance indicators on the four outcomes of interest. A survey of the eligible population before and after the intervention provided the data to determine changes in coverage rates or impacts resulting from the MGP interventions.

In Taytay, Rizal the interventions implemented under the MGP grant included the CBMIS; the provision of tetanus toxoid immunizations to eligible mothers of children attending day care centers, to women attending pre-marital counseling at the main health center, and to clients referred by private clinics and by an NGO health facility; and the provision of IUD services to the rural health unit ( $46 \%$ of the Taytay MGP grant was allocated to this last intervention). San Carlos on the other hand, implemented the CBMIS and strengthened their medical outreach program.

The process evaluation, which was a component of the overall impact evaluation of these areas, uncovered a number of implementation difficulties in both MGP areas. In Taytay, not all planned activities were implemented during the evaluation period. In fact, only four of the nine planned MGP interventions had been implemented at the time of the evaluation. Moreover, the provision of vitamin A supplementation in two critical areas could not be distinguished from the regular Department of Health program. There were also problems in service delivery related to insufficient supplies for TT2+ injections. The IUD kits that were purchased through the MGP grant were not yet delivered at the time of the survey. It is not surprising that with these implementation difficulties, the data reveal minimal outputs during the period of observation.

A similar situation was observed in San Carlos. The process evaluation found that several problems occurred during the medical outreach including: an inadequate supply of vaccines due to unanticipated migrant clients in need of services; lack of facilities and trained staff for bilateral tubal ligation referral; and difficulty in accessing natural family planning counseling sessions in remote areas.

These implementation difficulties and the limited time (six months) in which activities were studied are likely to limit the achievement of the potential impacts of these interventions. Indeed, the evidence of impact is mixed. There is some evidence of impact in Taytay with respect to immunization coverage for mothers and children. There was neither improvement in VAC coverage, nor a change in CPR, although use of modern

Policy and Program Implications of the Matching Grants Program in the Philippines 
methods increased. Evidence from San Carlos shows a decline in CPR and in TT2+, and no change in VAC coverage. However, FIC coverage appeared to have increased.

\section{Lessons for Planning, Implementing and Monitoring Health Interventions at the Local Level}

It is clear from the results of the impact evaluation that expected impacts from what might be inherently effective interventions can materialize only if they are implemented properly and as planned. Together with the results from the process evaluation, the evaluation results point to the following important considerations that are useful for planning, implementing and monitoring health interventions by local government authorities in order to maximize the impacts of such interventions.

Need for a good information system for planning, implementing and monitoring interventions. Initially, local government units in this study relied on FHSIS data, the only data available at that time, to analyze problems and set targets. The limitations of the FHSIS data for planning are well known, but they were a useful starting point. Indeed, the implementation of the interventions in all the study areas necessitated the gathering of new information regarding the unmet needs of potential clients. The CBMIS was found to be quite useful in identifying potential clients with unmet needs. Thus, it would appear that the CBMIS is a useful tool, providing the needed information for planning, implementing and monitoring health interventions, but the system requires a lot of investment in health workers' time, training and motivation to be sustainable.

A wide range of interventions are possible - some have larger outputs than others, but it is important to also consider the net output in assessing alternative interventions. One of the main features of the Matching Grants Program was that local government units, with some technical assistance, assessed their own situations and decided on the types of interventions to fund and implement. The findings from the process evaluation of the four pilot areas show that a wide range of interventions can be implemented. Some activities have larger outputs than others. For example, outreach activities can cover a larger segment of eligible clients than family planning referral programs for bilateral tubal ligation. However, it is not clear whether all clients who received services through outreach activities should be counted as the output of the outreach activities. It is possible that without the outreach, some of the potential clients would have gone to the health facilities for needed services anyway. The outreach activities simply gave them another opportunity to obtain service in a different way. The true output of the outreach is the number of clients who were provided services who would not otherwise have gone to health facilities or received services because they did not know there was a need, they did not know where to go, or because the facility was too far.

Focused interventions in some areas may detract from improving services in other areas. It is possible that the focus of MGP-related interventions may have detracted attention from other services, leading to a decline in coverage and quality of these other services. For example, in Dasmarinas rural health unit I, while performance improved dramatically for $\mathrm{TT} 2+$, there was a large reduction in the coverage rates for FIC and VAC

Policy and Program Implications of the Matching Grants Program in the Philippines 
(based on FHSIS data). This result suggests that efforts to focus on one outcome may displace other programs that are doing relatively well. Hence, local health managers should not lose sight of the larger local health sector plan, particularly routine activities that need to be maintained, when implementing new interventions such as those financed through the MGP.

Well-planned interventions can attract local funding and support. The Matching Grants Program experience suggests that, in addition to MGP funds and the local match, local governments were able to mobilize resources, whether financial or in kind, from various sources to implement their interventions. Sources of support included the Department of Health's regional and provincial offices, NGOs, and private drug companies. Local sources of funding and support are present in many communities. Well-planned interventions and advocacy are needed to attract this additional funding and support.

\section{Lessons for Developing Approaches to Assist Local Government Units to Achieve Local and National Health Goals}

Sustain important features of $L G U$ performance. Findings from the process evaluation of the four Matching Grants Program areas suggest a number of important features of LGU performance. First, local government are responsive to new ideas and adoption of new information technology such as the CBMIS. Second, they use innovative approaches to implement projects. One area used incentives to attract volunteers in worker-intensive activities like the CBMIS, one adopted a multi-pronged approach to deliver services to difficult to reach mobile populations in industrial areas. Finally, they have existing mechanisms for mobilizing other resources and community support, including the support of NGOs in the area, which are essential partnership in the effective delivery of key services.

It is not clear whether these features were inherent in the Matching Grants Program if or they were pre-existing characteristics in LGUs that predisposed them to participate in the MGP in the first place. Whatever the case, there is a need to encourage, support and sustain these important features.

Mobilization of funds: avoid displacement effects. There is a question on whether the MGP and matching funds, together with funds from other sources, really represented a net addition to the local governments' resources for health programs. These new funds may simply displace funds that would have been allocated to the health sector but are now available for use elsewhere, (i.e., local governments may actually reduce the budget for health by an amount equivalent to the MGP grant and other support received from collaborating agencies and NGOs). It is also possible that the government may be shifting resources away from other health programs to match the MGP funds. In the first case, there would be no net addition to health resources, and in the second case, there are less resources for other health programs.

The budget allocation data available are not adequate to provide definite answers to these questions. It was reported, however, that in Dasmarinas the P117,900 provided by the

Policy and Program Implications of the Matching Grants Program in the Philippines 
local government to match the MGP funds (MGP provided P400,000) was obtained by realigning funds already budgeted in 1999 for other purposes. MGP activities may actually have displaced funds for other activities whose performance may have suffered from reduced funding.

These findings suggest that grants to LGUs should be designed to provide guarantees for net additions to general health resources and for specific health interventions such as in the four priority program areas.

Cost-effectiveness field studies of selected interventions are needed to guide LGU choices. MGP recipients implemented different sets of interventions to improve the coverage of key services according to their assessments of the problems. It is still too early to determine which intervention had the most impact and at what cost. Costeffectiveness studies need to be done in the future to further assist local governments to make better investment choices. Some activities are likely to have little impact on overall coverage by themselves, (e.g., escorting family planning clients to services), while others are likely to be expensive in time and resources in the long run, relative to potential net increase in coverage (e.g., community outreach services where some clients would have gone to the clinics anyway).

\section{If political commitment to health is important for good performance it needs to be} developed. Who participated in the MGP program? Political commitment from participants (both in terms of joining the program and putting up matching funds) was essential. While political commitment was a precondition for the MGP grant, it would be useful from a policy standpoint to examine how a Department of Health grant program can build local government commitment to deliver effective and high quality health services.

Get smaller LGUs into the mainstream of policy support. The MGP program was designed for relatively large LGUs with populations of at least 100,000, which are likely to be economically and administratively better off than some of their small counterparts. Service delivery problems might be more severe in smaller, poorer LGUs. What types of program innovations are needed to work with these governments and achieve the Department of Health's Local Health System reform?

The MGP experience can help address larger issues of the DOH's health sector reform agenda. What are the larger policy issues that an intervention like the Matching Grants Program should consider? With decentralization, a common concern has been the "breakdown of the integrated referral system that existed when the public health sector was centralized and controlled by DOH" (DOH, 1999). How can MGP programs help put the referral system in place again in the context of decentralized administrative control? One approach that the Department of Health suggested to reintegrate the referral system is to develop local health systems. A local health system is a compellation of health services that facilitates resource pooling among different LGUs in order to achieve an effective and efficient referral system. The approach has yet to be put in place by DOH. Lessons learned through the MGP might be used in helping to institutionalize this

Policy and Program Implications of the Matching Grants Program in the Philippines 
approach. Benefits of the MGP programs include size (mid-size municipalities and component cities), technical assistance (through DOH and MSH personnel), interventions (selected by LGUs), and funds (MGP and matching funds). Municipalities that have rural health units and barangay health stations can link with provincial or district hospitals, as well as with private providers in their areas, to form an integrated referral system. These LGUs will have a common local health system plan and cost-sharing schemes. Technical assistance will be provided in health planning, mobilization and utilization of local health resources, and in linking up with private and NGO sectors. Finally, funds can be provided by $\mathrm{DOH}$ to fund critical elements in the formation of these networks.

Thus, while the old MGP focused on individual LGUs implementing interventions in four program areas, a new MGP might focus on a group of local governments to form an effective local health system to provide complementary services in a more integrated manner. For example, referrals for IUD insertions or removals, or for tubal ligations, would be more effective and better funded if the primary care center and the referred facilities were part of an integrated system administered and funded by several LGUs. This will prevent problems like LGU programs referring tubal ligation clients to hospitals out of their jurisdiction only to find that the service cannot be performed because of lack of trained personnel or funding at the referred facility.

In conclusion, the MGP process and impact evaluations provide valuable lessons, both for planning and implementing local health interventions that are effective, and for supporting local governments in expanding health service coverage in the context of health sector reform. 


\section{Appendix I \\ The MGP Performance Evaluation Study Experiences in San Jose del Monte, Dasmarinas, Tacloban and Digos, Philippines}

\section{Marilou Palabrica-Costello}

Ma. Teresa I. Manganar

Zimmbodilion Mosende

With the assistance of:

Roxanna B. Epe

Roy A. Dimayuga

Alberta S. M. Vargas

March 2003 


\section{SUMMARY}

In 1999, the Matching Grants Program was initiated as a new component of the Local Government Performance Project (LPP), a five-year initiative undertaken by the Philippine Department of Health (DOH), USAID and Management Sciences for Health (MSH). The Matching Grants Program (MGP) was developed as an incentive for local government units (LGU) to strengthen their delivery of health services. More specifically, the MGP aimed at improving the capabilities of local governments to effectively expand service delivery in such a way that its impact would be demonstrable. Four programs targeted for improved service delivery were identified: (1) Full immunization for children (FIC); (2) vitamin A supplementation coverage (VAC); (3) tetanus toxoid two-plus (TT2+) coverage for women; and (4) the use of modern contraception for family planning (FP). Local governments participating in the MGP determined the programs and ways to implement them to improve the health of their community in those four program areas.

\section{Purpose of the MGP Evaluation}

This report documents an evaluation of the MGP conducted between 1999 and 2000 by the Frontiers in Reproductive Health Program, in cooperation with Management Sciences for Health, at the request of USAID Manila. This activity falls under FRONTIERS' USAID IR 1: Testing Innovative Solutions to Reproductive Health and Family Planning Service Delivery. The objectives of the study were two-fold: (1) To evaluate the relative effectiveness of the various local government interventions funded by the MGP in reaching under-served and high-risk populations in need of health services; (2) To evaluate evidence from four selected local government units to determine if the interventions resulted in higher levels of coverage in the four programs targeted by the $\mathrm{DOH}$ for improved service delivery. The evaluation was conducted in two phases. This report, representing Phase 1, concentrates on the processes involved in the MGP in the four selected locations. Another report focuses on Phase 2, which concentrates on the outcomes of the MGP and its overall impact in two selected LGUs. Collectively, the reports for Phase 1 and 2 evaluate whether the different interventions led to significant improvements in the four targeted health program areas.

FRONTIERS staff conducted performance evaluations between June 1999 and March 2000 in four local government units, namely: (1) San Jose del Monte, Bulacan; (2) Dasmarinas, Cavite; (3) Tacloban City, Leyte; and (4) Digos, Davao del Sur. The evaluations measured program performance by monitoring various inputs, processes and outputs. The design for the Phase 1 evaluation utilized qualitative methods that documented performance levels through observations, in-depth interviews with key informants, and analysis of programbased data.

The information gathered at each of the four research sites is categorized in the following ways:

- Characteristics of the study area (including population statistics, the status and system of healthcare delivery and current health budgets) 
- Planning and implementation of MGP interventions

- Highlights of the implementations (innovative strategies and problems encountered)

- Overall outputs of MGP and changes in service coverage in the four target health areas

Following the data presented for each individual site is a synthesis of the overall MGP experience. Particular attention is given to the amount of effort local governments invested in planning and implementing their MGP interventions. This section also looks at the limitations and strategies of local government officials in identifying local health problems, which directly affected the types of interventions they chose. Also documented are the processes and effects of new components added in each of the study sites, such as how new health information technology was integrated and how networks of nongovernmental organizations were mobilized to implement the interventions. Where possible, the report presents preliminary findings on how services were expanded in the research sites.

One highlight of this report is the section "Utilization of Study Findings." Examples demonstrate how specific findings resulted in policy shifts in program implementation as documented during midstream evaluations by FRONTIERS staff. This section describes how the Department of Health and Management Sciences for Health utilized the findings. Particularly noteworthy are the shift in criteria used to enroll MGP applicants in the program, and the modification the funding payment schedules to the local government units based on initial findings. The "Conclusions and Recommendations" section raises policy issues. Of particular interest is the question of whether the MGP match and local government funds, together with funds from other sources, really represent a net addition to the local governments' resources for health. The issue is whether these new MGP funds simply displaced funds already allocated to the health sector. The evaluation report concludes with a review of the role stakeholders play in implementing the Matching Grants Program and identifies four significant lessons learned:

1. Local governments are responsive to new ideas, as shown in the adoption of the Community-Based Management Information System (CBMIS).

2. Local governments are innovative in many respects, such as in their use of incentives to attract volunteers for labor-intensive activities, or adopting multipronged approaches to deliver services to difficult-to-reach mobile populations in industrial areas.

3. A review of performance outputs shows positive results, especially in the target program areas.

4. Local governments have identified innovative mechanisms for identifying and mobilizing other resources in the community, including the support of NGOs and the private sector. 


\section{ACKNOWLEDGMENTS}

The authors wish to acknowledge the inputs of Dr. Alejandro Herrin, Dr. Nimfa Ogena of the University of the Philippines, and Robyn R. Canham of Ateneo de Manila in the analysis and preparation of this report. We appreciate the guidance and input of Dr. Dale Huntington, Asia and Near East (ANE) FRONTIERS Regional Associate Director in the development of the evaluation project.

We thank Dr. Cecilia Acuin who served as project coordinator of the Evaluation Study and supervised the implementation of the field work, collection, and processing of the MGP data. Her early reports on the MGP project helped to synthesize the voluminous field notes and reports by field evaluators.

We likewise thank many people whose names cannot all be acknowledged individually, particularly the local government officials in the four MGP evaluation sites. They have been generous with their time and facilitative of the work of the evaluation teams in their respective areas.

It was a pleasure working with the staff of Management Sciences for Health. Their sense of professionalism made the task of evaluating the MGP a meaningful learning experience for the team in many ways. We thank them for their cooperation and openness, and for sharing with us documents needed to plan for and implement this study, which greatly facilitated the evaluation work.

We thank the members of the USAID Mission for their support of this project. Mr. Ephraim Despabiladeras deserves special mention for his committed support of the value of including an evaluation component in MGP. We are grateful to Melissa Howell for her expert assistance in editing the final version of this report under severe time constraints. 


\section{BACKGROUND}

The local government unit Performance Program (LPP) is a five-year (1995-2000) USAIDassisted project with the objective of improving the "health of mothers and children by increasing the utilization of family planning, maternal and child health, and nutrition services." The LPP strives to increase the capacity of local government units (LGUs) to manage health programs by providing both financial and technical assistance. Provinces and highly urbanized component cities were enrolled in the program through a memorandum of agreement "to implement a comprehensive plan on population, family planning and child survival program." LPP grants are therefore designed to serve as incentives, encouraging LGUs to adopt best practices in the distribution of commodities, the training of staff, the equipping of service delivery sites, the provision of voluntary sterilization services, and the use of information, extension and communication materials (IEC). ${ }^{3}$

Data from the 1998 NDS and the Midterm Assessment in June 1998 raised the issue of whether the LPP has had any direct impact on delivery of reproductive health/family planning services. The assessment report concludes that while the LPP is "an effective vehicle for developing LGU management and service delivery capability," it may not be the most appropriate means for achieving impact on health objectives. The report recommended a "follow-on initiative" that can put greater emphasis on impact, building on the strengths of the LPP, while overcoming its limitations.

\section{The Matching Grants Program: The "Follow-On Initiative" of LPP}

The above recommendation became the basis for the development of the Matching Grants Program (MGP). The Matching Grants Program is designed to stimulate local government units to focus directly on strengthening service delivery, giving them more latitude in determining their local programs. Consequently, the MGP was developed with the following well-defined features: ${ }^{4}$

- Targets mid-sized cities and municipalities, initially those with populations of 100,000 and above, where

\section{MGP Features}

- Targets mid-sized cities and municipalities, with populations of 100,000

- "Grantee-friendly" application process, with the $L G U$ defining its own goals and program direction

- Flexible funding of up to PhP 500,000 and access to technical assistance

- Funding allocation designed for MGP-assisted programs through a "match" or counterpart fund

\footnotetext{
${ }^{3}$ Reynolds, Jack, et al. 1998. "Midterm Assessment of Intermediate Result 1 of Strategic Objectives 3 "Increased Public Provision of Family Planning and Maternal and Child Services". POPTECH Report No. 97127-067.

${ }^{4}$ MSH. 2000. "Matching Grant Program (MGP): An Innovative and Responsive Program for Expanding 3 MSH, 2000 Service Delivery and Enhancing Quality of Care," pp. 1-2.
} 
- Employs a "grantee-friendly" application process, with the LGU defining its own goals and program direction.

- Provides flexible funding of up to 500,000 Philippine pesos and access to technical assistance.

- Encourages LGUs to increase funding allocation and expenditures for MGP-assisted programs through a "match" or counterpart funding.

MGP Objectives. The MGP aims to improve the capability of municipalities and component cities to expand service delivery, and to achieve significant and measurable impact on the following four Department of Health $(\mathrm{DOH})$ program areas:

1. Fully immunized children (FIC)

2. Vitamin A supplementation coverage (VAC)

3. Tetanus toxoid two plus (TT2+) coverage for women

4. Use of modern contraception (CPR) to reduce unmet need for family planning.

\section{OBJECTIVES OF MGP EVALUATION STUDY}

USAID Manila called upon the Frontiers in Reproductive Health Program to work closely with Management Sciences for Health (MSH) to conduct an evaluation of the MGP during 1999-2000. The objectives of the evaluation study are:

1. To evaluate the relative effectiveness of various interventions funded by the MGP in reaching underserved and high-risk populations with needed services.

2. To evaluate evidence of direct impact in selected LGUs, as measured by the contraceptive prevalence rate (CPR), childhood immunizations (FIC), tetanus toxoid vaccination among pregnant and married women of reproductive age (TT2+), and vitamin A use (VAC) among children between the ages of 12-59 months.

These objectives are directly related to the FRONTIERS program's Intermediate Result 1: Testing innovative solutions to reproductive health and family planning service delivery. The evaluation study provides detailed information on the operations and impact of the MGP. It will be used by the Department of Health and local government officials to develop policy, improve program management, and refine the design of subsequent MGP programs in the Philippines. 


\section{RESEARCH DESIGN}

Due to the rapid implementation and timetable of the MGP, the evaluation proceeded in two phases. Phase 1 is the process or monitoring evaluation. This phase evaluated the process and outputs (performance) of the first set of MGP participants. Phase 2 consists of process and impact evaluation and assessed both program performance and outcomes. The primary objective is to determine whether different interventions (or mixes) will lead to significant increases in the four targeted indicators. The timeframe for observing changes was six months. The evaluation used the

\begin{tabular}{l}
\multicolumn{1}{c}{ Study Phases } \\
Phase 1: \\
Process or monitoring \\
evaluation \\
Phase 2: \\
Process and impact \\
evaluation \\
\hline
\end{tabular}
"input-process-output-outcome" framework as shown in Figure 1.

Figure 1. Conceptual Framework Showing Links of the Program Components to the Outcome Indicators and the Different Categories of Evaluation Indicators

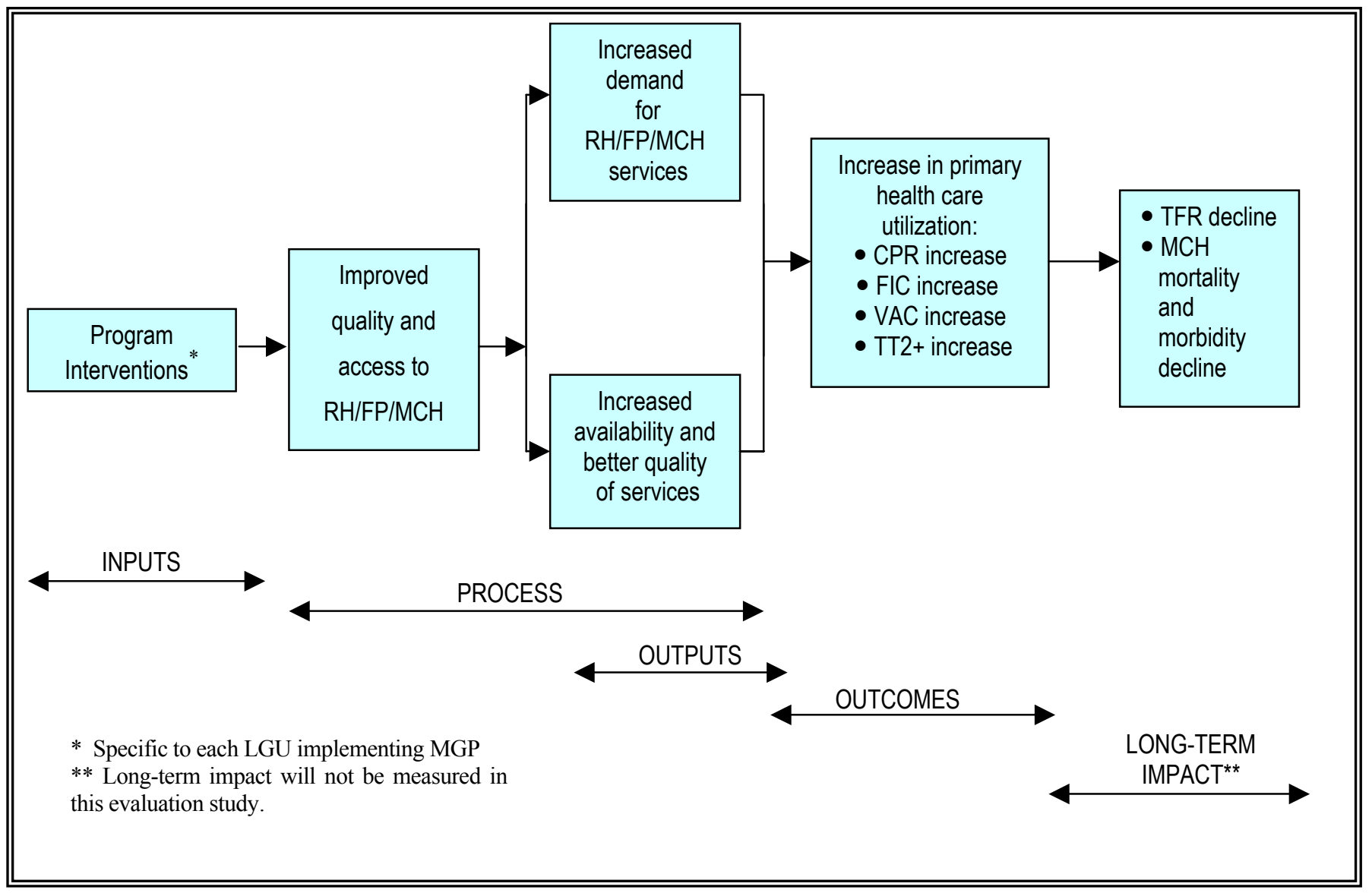




\section{Process and Monitoring Evaluation of Four MGP Sites}

Phase 1 employed qualitative methods whereby Matching Grants Program inputs, processes, and outputs are documented in the field through observation, in-depth interviews of key informants, and analysis of program-based data. ${ }^{5}$ Sites were observed on a regular basis to ascertain whether program activities were being implemented according to plan, and to assess how well the activities were performed and utilized.

Site Selection. Municipalities and cities had to meet a number of established criteria to be selected to participate in the MGP. These included:

- Availability of matching funds

- Clearly defined activities and budget

- Activities should increase utilization of services among target clientele

- Activities should result in increased coverage

- Activities should be discrete and have a reasonable chance of obtaining measurable impact within 12 months or less

The following LGUs were selected for Phase 1 of the evaluation study: 1. San Jose del Monte, Bulacan (Cluster A); 2. Dasmarinas, Cavite (Cluster B); 3. Tacloban, Leyte (Cluster C); and 4. Digos, Davao del Sur (Cluster D).

\section{Impact Evaluation of MGP Sites}

Essentially, Phase 2 is an outcome evaluation (Figure 1). It measures the immediate effects of the MGP interventions on specific program indicators utilizing a quasi-experimental pretestposttest nonequivalent groups design. Outcomes were evaluated using data from population surveys and situation analyses. Inferences about impact are based on the empirical analysis of outcomes (i.e., the direct and immediate result of program process and output), and plausible alternate hypotheses.

Site Selection. The original plan for selecting the impact sites was to randomly select them from the second batch of MGP recruits. ${ }^{6}$ However, because MGP was implemented on a "first come, first served" basis, it was not possible to randomize the selection procedure. In the end, the intervention sites were selected because of the availability of suitable control sites within their provinces. All the selected LGUs are cities and municipalities in the highest

\footnotetext{
${ }^{5}$ While every effort was made to ensure complete documentation of the MGP, there were key activities that were not observed by the field evaluator. For example, the planning stage for one of the MGP areas was not observed because this occurred before the evaluation study team was organized. To address this gap, key informant interviews were conducted to elicit information on what exactly happened during the planning activities.

${ }^{6}$ The selection of the three intervention LGUs was further limited by two additional factors: 1) the rate at which MGP is being implemented (LGUs who had not yet been oriented and did not have a work plan on which the baseline assessment could be made could not be part of the pool for selection of sites for the impact evaluation), and 2) since the intervention LGU had to have a control LGU from the same province, this precludes the selection of LGUs where all MGP-qualified units of the province have been recruited at the same time leaving no possible control.
} 
income category classification by the Department of Finance. The three sites chosen were Taytay in Luzon, San Carlos in the Visayas, and Tagum in Mindanao. These sites did not initiate MGP activities before the baseline assessment was made.

Intervention and control sites were

Figure 2. The MGP Process and Monitoring Sites matched on the following criteria: 1) both in the same province to control for administrative and other forms of support from the province level, 2) similar population sizes, 3) same income category, and 4) similar baseline performance on the four indicators of interest (FIC, TT2+, VAC and CPR). Because there are considerable differences in the level of economic development in different regions, pairs were selected in Luzon, Visayas and Mindanao - the three major geographic divisions of the country. Taytay-Binangonan, San Carlos-Cadiz, and Tagum-Panabo are the intervention and control sites chosen for the impact evaluation. Because of delays in implementation of the program interventions in Tagum, this set of sites (Tagum-Panabo)

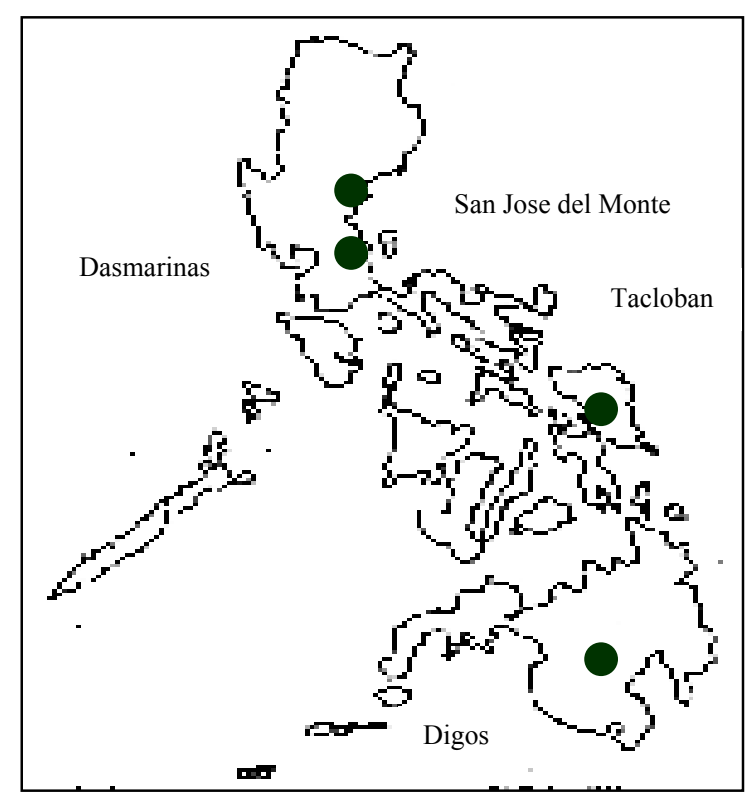
was dropped from the final impact evaluation. In the end, only two sets of comparison sites were included in Phase 2 of the study.

This section presents the process and monitoring evaluation results for Phase 1 of the MGP evaluation study. Figure 2 provides a map of the Philippines and study sites. Major findings are described for each of the four study areas organized as follows: (a) a brief description of the study area, (b) planning of the MGP interventions, with attention to the LGU analysis of problem areas and choice of interventions, (c) evaluation of the implementations, focusing on aspects including the application of new health information technology through the Community-Based Management and Information System (CBMIS), mobilization of new resources and expansion of health services, and innovations in service delivery, and (d) data on outputs and, in some instances, service coverage for the four key services.

\section{MGP PERFORMANCE IN INDIVIDUAL STUDY AREAS}

This section reviews the Matching Grants Program experience in four evaluation sites. More detailed analysis of the MGP performance in each of the four sites is reported in four separate site-specific reports (available from the Population Council, Manila). 


\section{San Jose del Monte, Bulacan}

\section{Characteristics of the Area}

Population. The population has grown rapidly from 169,424 in 1994 to an estimated 269,083 in 2000 , for an average annual increase of 8.4 percent. Massive squatter relocation and an increasing number of low-cost housing projects have contributed to this rapid growth in population.

Health care delivery system. San Jose del Monte is divided into two informal divisions. The first is the urban resettlement area, which is served by three rural health units located in the villages (barangays) of Minuyan, Bagong Buhay, and Sta. Cruz. The second is the nonresettlement area, informally identified by the local government unit as the "non-area," and served by two rural health units, 11 barangay health stations (BHS), and 25 barangay substations. Together, the two rural health units serve a population of 120,718 , comparable to a medium-sized town. The Matching Grants Program covers all 24 barangays in the nonresettlement area. Many private clinics also operate in the area.

Health budget. The health budget increased from 1.5 million pesos in 1994 to 4.5 million pesos in 1999, representing 3.4 percent and 4.2 percent of the total local government budgets, respectively. On the average, 75 percent of the budget was allocated for personnel services during the period and only 25 percent was allocated for maintenance and operating expenses.

\section{Planning the MGP Interventions}

Based on the review of available staff and health facilities and the 1998 program performance for the four indicators, a MGP health team (comprised of a regional technical assistant from Management Sciences for Health, a local rural health physician, and other local health workers) determined that the family planning program needed the most attention. Data showed that the contraceptive prevalence rates in the two rural health units were 24 and 29 percent. The coverage rates for TT2+, FIC and vitamin A appeared to have been met (i.e., coverage of 100 percent or more), although the usual problems remain in estimating the target-based projected population and fixed factors for estimating eligible population. The population denominator can easily be underestimated in rapidly growing areas like San Jose del Monte, resulting in overestimated coverage rates for the program indicators. Hence, the low contraceptive prevalence rate recorded may in fact be even lower.

Through the Matching Grants Program, San Jose del Monte set as its goal an increase of 10 percentage points in CPR from 1998 levels, while maintaining high coverage rates for the other indicators. Their MGP activities were implemented in two of the municipality's five rural health units, namely RHU I and RHU II. 


\section{Implementation of the MGP Interventions}

San Jose del Monte, guided by its MGP health team, focused activities on family planning services. The key activities implemented were:

- Implementation of the Community-based Monitoring and Information System (CBMIS). CBMIS can be used to identify eligible populations with unmet needs for the four program services and to provide on-site services. In San Jose del Monte, it was expanded for use in other health programs including the use of growth monitoring charts, promotion of iodized salt, and monitoring of environmental sanitation, as a result of discussions among the health staff.

- Community service outreach. These activities aimed to provide services to clients identified to have "unmet needs" based on the CBMIS data. Services included clinicbased outreach activities, house-to-house visits to old and new clients who are eligible for the services, and setting up temporary centers in remote areas to provide family planning and other services for children and mothers.

- Revival of IUD services in rural health centers. No midwives were trained to provide IUD services in the two rural health centers. Plans were made to have midwives trained in IUD insertion and removal, but in the meantime, a referral system for IUD services was set up with Sapang Palay District Hospital.

- Networking with a district hospital for VSS referrals. Voluntary surgical sterilization (VSS) clients were referred for services at district hospitals. The MGP covered their transportation costs and provided an accompanying health provider.

- Additional activities as offshoots of the MGP. Utilizing information obtained from the CBMIS, other activities were implemented including the Mother-Baby Watch Program, a salt iodization program, a solid waste segregation program, and a data health board. The MGP served as a catalyst for these other programs.

\section{Highlights of Implementation: Innovations and Bottlenecks}

Incentives for maintaining the CBMIS. Due to the labor-intensive nature of implementing and maintaining the CBMIS, San Jose del Monte provided incentives to volunteer barangay health workers (BHWs), allowing them to sell iodized salt during their house-to-house visits. The incentive appears to have been effective not only in retaining volunteers, but also in expanding their number from 99 to 200 .

The call slip system. Clients with unmet needs identified by the CBMIS were given a call (referral) slip. People with call slips were given priority during the outreach services, especially the clinic-based outreach. Those requiring non-MGP services were also given call slips for services to be obtained in the regular clinics. The call slip system ensured that priority clients were served without alienating those who came for non-MGP services. This 
eased pressure on staff who are usually overwhelmed by the number of people who come for services.

Sustainability of community outreach activities. Due to the lack of health workers, health workers from other areas volunteered to help in the target community during the outreach activities. While this approach worked for a while, it will be difficult to sustain these activities in the future without additional incentives for volunteer outreach workers.

\section{Outputs and Service Coverage}

Outputs. Through the CBMIS, underserved populations were identified for community outreach. Close to 6,000 clients (from both RHU I and RHU II) were referred through call slips, of which 73 percent responded by seeking out the needed service, either through community outreach activities or at the clinic. For the call slips approach to work, however, sufficient motivation and initiative on the part of the clients is required. Barangay health workers played a substantial role in motivating clients to respond to call slips.

Community outreach activities covered all 24 barangays of RHUs I and II by March 2000. IUD service was hampered by a lack of trained staff and equipment. With the retirement of the only staff member trained in IUD insertion and removal at RHU I, an attempt was made through the MGP to equip RHU II to provide IUD services. However, training is not within the scope of MGP. A referral system with Sapang Palay District Hospital was arranged, and as of April 2000, 13 clients received IUD insertions. RHUs I and II also referred three clients for tubal ligation to the Sapang Palay District Hospital in 1998, three in 1999, and four in 2000 (as of April 2000).

Service coverage. The accomplishments of the MGP in San Jose del Monte for contraceptive prevalence are summarized in Table 1, based on Field Health Services Information Services (FHSIS) data. FHSIS data are limited, as denominators are based on projections of local populations (based on the national population growth rate). In the case of San Jose Del Monte, as in the other three MGP areas, the denominators used are too small as local population growth exceeds the national average. Hence, coverage rates appear to go beyond 100 percent. Because of the unreliability of the FHSIS, the CBMIS intervention was proposed. Given that FHSIS was the only existing data in the early phases of the intervention, it still proved useful in MGP program planning.

San Jose del Monte's levels of coverage after the introduction of MGP interventions are uniformly higher for each indicator, compared to the expected outcomes. It is too early to tell if these changes are due solely to the MGP interventions, however, the program indicators all showed positive changes. In fact, CPR almost doubled in 1999 in RHU II. 
Table 1. Comparison of Program Outcomes Based on FHSIS Figures San Jose del Monte, 1998 and 1999

\begin{tabular}{lccccl}
\hline \multirow{2}{*}{$\begin{array}{l}\text { Performance } \\
\text { Indicators }\end{array}$} & \multicolumn{2}{c}{1998} & \multicolumn{2}{c}{1999} & $\begin{array}{l}\text { Expected MGP } \\
\text { Outcome }\end{array}$ \\
\hline CPR & RHU I & RHU II & RHU I & RHU II & \\
TT2+* & $29.4 \%$ & $23.8 \%$ & $53.0 \%$ & $52.5 \%$ & $34-39 \%$ \\
FIC* & $105 \%$ & $102 \%$ & $114 \%$ & $135 \%$ & $100 \%$ \\
VAC* & $114 \%$ & $119 \%$ & $112 \%$ & $130 \%$ & $100 \%$ \\
\hline
\end{tabular}

Source: $R H U$ records

*Coverage rates go beyond 100\% because denominators are estimates based on national figures.

\section{Dasmariñas, Cavite}

\section{Characteristics of the Area}

Population. Dasmariñas is a rapidly industrializing town with an estimated population of 363,083 (1999). The rapid growth of the population in Dasmariñas since 1980 is related to patterns of urban resettlement in the 1980s and rapid economic development in the mid1990s. The town recently became the site of the First Cavite Industrial Estate. The industrial part of town now hosts more than 50 factories producing electronics, food and garments. Dasmariñas is also known as the "University Town" of Cavite because it is home to several large universities and educational institutions that were established in the last decade.

Health care delivery system. The Cavite Provincial Government operates the Dasmariñas municipal hospital. The town supports two rural health units and 74 barangay health stations to serve the community's primary health care needs. Each RHU is administered independently, with its own staff, facilities and catchment areas. The midwife-to-population ratio is close to the Department of Health recommended 1:5,000; however, the government physician-to-population ratio is considered far below standards in both RHU catchment areas.

According to RHU physicians, the community also lacks sufficient barangay health workers, with only 161 in both RHUs. The RHU physicians attribute this shortfall to local women's preference to work and earn wages rather than volunteer at the health centers. This is not surprising given the level of industrialization and the availability of jobs in the area. Two private tertiary hospitals complement the public sector facilities.

Health budget. For the past five years, Dasmariñas has allocated about 7 percent of its budget for health. In 1999, 14 million pesos were allocated for health. About two-thirds of the municipal health budget goes to personnel services, with the remainder allocated to maintenance and operating expenses. 


\section{Planning the MGP Interventions}

A review of program indicators in the four key areas by local MGP health authorities showed that, in 1998, both RHUs had adequate performance in the areas of child immunization and vitamin A supplementation. However, the performance in tetanus toxoid coverage and family planning use were relatively low. The coverage rate for TT2+ was only 24 percent in 1998, while estimated contraceptive prevalence was only 11 percent. As a result, the MGP plan focused on improving TT2+ and family planning coverage.

In Dasmariñas, the $M G P$ focused on improving tetanus toxoid and family planning coverage.
Local health authorities attributed low performance in TT2+ coverage to the following factors: a common misconception among women that one dose of TT is sufficient, the tendency for pregnant mothers to visit rural health units for prenatal checkups only just before delivery, many women are migrants and find it difficult to access needed services, and women in employed factories may not find health centers' schedules convenient.

With respect to family planning, part of the difficulty experienced in service provision by the RHUs was the lack of IUD kits and other equipment in the barangay health stations.

\section{MGP Program Implementation}

With the choice of TT and FP as the focus of MGP in Dasmarinas, the following activities were selected for MGP resources:

- Community-Based Management and Information System (CBMIS). To keep track of their large, mobile population, as well as the services they may have used in the private sector, the existing master list was updated monthly to determine Expanded Program on Immunization, family planning and vitamin A supplementation coverage status to identify those with unmet needs.

- Three-pronged approach to improve TT2+ coverage. This approach was adopted to follow up TT2+ defaulters, as well as first time TT clients:

1) BHS EPI team approach. Before the MGP, midwives administered only child immunization during EPI days. Through the MGP, nurses were deployed to cover the barangay health stations so that mothers bringing their children for immunizations who were eligible for TT could also be served.

2) Home visits to follow up TT defaulters. Pregnant and postpartum women who fail to return for their next TT dose are sent reminder letters by barangay health workers. If the woman still fails to come to the clinic, the midwife pays her a visit at home as an opportunity to correct misconceptions about TT. 
3) Industrial site visits for TT2+. Letters were sent to factories within the municipality informing them of the provision of TT immunization to eligible female workers. Nurses visited those interested in the service and administered the TT injection on a pre-arranged schedule.

- Provision of IUD equipment to BHSs with trained midwives. Ten midwives who were trained in IUD insertion and removal were given IUD kits enabling them to provide services at the BHS. Before, IUD services were provided only at the RHUs.

- Escort services for potential VSS clients. Voluntary surgical sterilization is offered at the municipal hospital, located in Dasmariñas Bagong Bayan (DBB). However, this hospital is not easily accessible to those residing in the town proper. The MGP provided funds for transporting clients to the DBB hospital for VSS.

- Training of traditional birth attendants. Traditional birth attendants were trained on aseptic delivery techniques through the municipal health office. With the MGP, referrals for tetanus toxoid and family planning services were also emphasized.

\section{Highlights of Implementation: Innovations and Bottlenecks}

The establishment and use of CBMIS required a number of prior activities. First, a standard form was developed. A group of doctors, nurses, midwives, and barangay health workers attended a "write shop" to develop a standard instrument for master listing. Second, barangay health workers were trained to use the algorithm for determining unmet needs for family planning and to provide the appropriate services. The training uncovered a number of problems including difficulty in administering the English-language instrument.

The CBMIS required a large amount of staff time. It took six months to implement the CBMIS in RHU II. The rural health units gave non-monetary incentives to the barangay health workers who implemented the system, including vests and T-shirts, which also served to show to the community that the survey was an official activity of the local health units.

Making the CBMIS truly community-based may be limited by the capabilities of the barangay health workers who are responsible for data collection and initial data processing. In Dasmariñas, the BHWs were responsible for data collection only and midwives took charge of the data processing, an additional workload for the midwives. BHWs need to be trained in data processing and utilization, and provided incentives to participate in this program.

\section{Outputs and Coverage of Program Services}

Outputs. With the application of the CBMIS, RHU II covered 27,562 households in six months. There was a sharp increase in service provision (at least doubled) with respect to TT2+ and family planning between the last two quarters of 1998 and the last two quarters of 1999. For example, the number of pregnant women given TT2+ was 461 in the fourth quarter of 1998 . This rose to 1,225 in the fourth quarter of 1999. Similarly, the number of family 
planning acceptors rose from 681 to 1,393 during the same interval. The performance on child immunization (FIC), however, has remained about the same.

Service provision. For RHU I, data show that while performance improved dramatically for TT2+, it has remained relatively the same for family planning. RHU I has had a drastic reduction in FIC and VAC performance. Like RHU I, RHU II's VAC performance has declined. The staff from both RHUs attributed this to a lack of vitamin A capsules for distribution. These results need to be considered in assessing the overall effectiveness of the MGP, as efforts to focus on one outcome may displace other programs that are doing relatively well (Table 2). Further, we must consider that the 1998 data for VAC and FIC is based on FHSIS data, which, as discussed in the case of San Jose del Monte, may have already been inflated.

Table 2. Comparison of Program Outcomes Based on FHSIS Figures, Dasmarinas, 1998 and 1999

\begin{tabular}{lcccc}
\hline \multirow{2}{*}{ Performance Indicators } & \multicolumn{2}{c}{1998} & \multicolumn{2}{c}{1999} \\
& RHU 1 & RHU II & RHU 1 & RHU II \\
\hline CPR & $53 \%$ & $24 \%$ & $50 \%$ & $46 \%$ \\
TT2+* & $36 \%$ & $45 \%$ & $107 \%$ & $80 \%$ \\
FIC* & $120 \%$ & $99 \%$ & $75 \%$ & $101 \%$ \\
VAC* & $138 \%$ & $92 \%$ & $91 \%$ & $87 \%$ \\
\hline
\end{tabular}

Source: RHU records

*Coverage rates go beyond 100\% because denominators are estimates based on national figures.

\section{Tacloban, Leyte}

\section{Characteristics of the Area}

Population. Tacloban City, the capital of Leyte Province, is the hub of economic development in the Eastern Visayas. As such, it attracts a steady flow of migrants from less developed areas, particularly northern and western Samar. This migration contributes to an annual population growth rate of 3.8 percent, which is 1.5 percentage points higher than the national growth rate. This large transient population exerts tremendous pressure on the city's limited health care delivery systems.

Health care service delivery system. The city health office has only one health center providing family planning services to the city's 201,997 residents (projected population in 2000). There are 13 barangay health stations serving 138 barangays. As elsewhere in the Philippines, midwives provide the backbone of the health system's primary care services. While the ideal provider (midwife) to barangay ratio is $1: 1$, the

While the ideal midwife to barangay ratio is $1: 1$, the ratio in Tacloban is only 1:8, implying a significant shortage of health care personnel. 
ratio in Tacloban is only 1:8, which implies a significant shortage of health care personnel.

At the community level, the city health office supervises 225 barangay health workers and the city population office oversees 133 barangay supply point officers. On average, the BHW-household ratio is in the order of 1:100-150. Many barangays have only one BHW who serves simultaneously as its supply point officer. In general, the BHW assists the general health program, while the supply point officer specializes in family planning activities. The majority of these community-based workers are volunteers.

The majority of community-based workers are not compensated for their outreach activities.

Health budget. The health budget in Tacloban increased from 7 million pesos in 1994 to 14 million pesos in 2000. As a percentage of the total city budget, however, it declined from 5.2 percent in 1995 to 3 percent in 1999. In 2000, it rose to 4.2 percent of the total city budget. Additionally, a large part of the health budget (about 70 percent on the average during the study period) is allocated for personnel expenditures (only 30 percent is allocated for maintenance and operations). This limits expenditures on much-needed drugs, supplies, repairs, and maintenance, as well as travel allowances for outreach activities.

\section{Planning the MGP Interventions}

Based on available data, the city has attained high performance through its Expanded Program on Immunization and vitamin A supplementation. In contrast, TT2+ and CPR for modern methods indicate low coverage of 56 percent and 6 percent, respectively, in 1998. Tacloban chose interventions dealing with all four areas of concern. The city authorities attribute the low coverage rate for tetanus toxoid to the misconception among women that the vaccine causes sterility or miscarriage. On the other hand, the low modern

The interventions focused on the four areas of concern namely: $T T 2+, F P, E P I$ and $V A C$. contraceptive use was attributed to a fear of side effects such as increased blood pressure, vomiting, dizziness, and headaches associated with the pill, and bleeding associated with IUD use.

\section{Implementation of MGP Interventions}

Tacloban implemented activities to deal with the four areas of concern, namely: TT2+, FP, EPI and VAC. Their activities included:

- Community-Based Monitoring and Information System (CBMIS) to identify clients in need of services.

- Conduct of Family Health Day and home visits for "mop-up operations." Activities included child immunization, family planning and reproductive health services, vitamin A supplementation, medical consultation, dental health services, and health education through puppet shows. 
- Provision of family planning and tetanus toxoid services during the social hygiene clinic and pre-marital counseling. The integration of family planning services and tetanus toxoid immunization in the social hygiene clinic and premarriage counseling is a new city health office strategy under the MGP. The intervention is tailored to capture missed clients who cannot make use of services provided during the regular schedule in health facilities.

- Partnership with nongovernmental organizations (NGOs) in expanding service delivery. NGOs provided surgical sterilization and IUD services. The MGP supports the cost of client transportation to the facility and covers the service fee incurred. The MGP also provided some of the supplies needed for the services.

\section{Highlights of Implementation: Innovations and Bottlenecks}

As in the other MGP areas, there were initial bottlenecks in implementing the CBMIS in Tacloban. ${ }^{7}$ When initial problems were resolved, however, the city health office found the CBMIS to be a useful tool, not just for obtaining information about their clients, but for facilitating service delivery as well. The CBMIS has allowed the program to assess potential demand for services in the community.

A number of areas regarding the CBMIS need to be addressed. Foremost are the time and staff resource needs. Tacloban has not found it efficient to utilize their barangay health workers or supply point officers for this intervention, instead using midwives and nurses to conduct the CBMIS program. How this approach will affect the sustainability of the CBMIS is still in question, given the limited number of health personnel in the city health office. There is also a need to improve data processing and consolidation, particularly during updating and follow-up of clients.

The health mop-up operations through Family Health Day required a number of preparatory activities. These included using the CBMIS to identify clients in need of services, mobilizing the community, local officials, health workers, and other stakeholders (NGOs, other government organizations, academe, and drug companies).

The success of the activity depended on the support of many stakeholders. Logistical support, medicines and supplies from the Department of Health, the Provincial Health Office, and the GLAXO drug company augmented the activity's resource requirements. Active involvement of barangay health workers, supply point officers, and nutrition scholars and the facilitative efforts of local barangay officials were crucial in community mobilization. NGOs (LEFADO

\footnotetext{
${ }^{7}$ Problems that arose in the actual conduct of CBMIS included the following: two versions of the survey instrument were used at the time when the CBMIS as a process was evolving; the orientation was not so clear at the start; the reproduced copies of CBMIS tool were not legible; difficulty of BHWs and BSPOs in identifying unmet needs and translating unmet need into service provision or providing the appropriate action to be taken; and conflicting issues on who and how to process and consolidate the data or survey results.
} 
and the Marie Stopes Foundation), the City Population Office, the Leyte Institute of Technology, and the Remedios T. Romualdez Medical School provided strong partnerships in advocacy and service provision.

\section{Outputs and Coverage of Program Services}

Outputs. As of March 2000, a total of 3,446 clients for FP, EPI, TT2+, vitamin A and other curative services combined were referred to clinics (public and private sector) since the completion of the master listing in August 1999. Data showed that 326 children (38.9\% of the 838 target population) were fully immunized during Family Health Days held in the intervention period, while 139 pregnant women (45.7\% of the 304 target population) received TT2+. Moreover, 606 (34.4\% of 1,760) married women of reproductive age with unmet need for family planning were served, reducing unmet need to 81.4 percent.

Forty-seven of 649 clients in social hygiene clinics availed of tetanus toxoid immunization. Of these, 22 clients received the first TT dose. Moreover, 271 (91.7\%) of 279 women of reproductive age attending pre-marriage counseling received TT immunization. Of these, 248 (89\%) had their first dose, 5.4 percent received TT2, and 1.1 percent were given TT3.

NGO clinics helped expand the service delivery network in Tacloban. Of 51 tubal ligation clients, 28 were supported by the MGP. The number of clients ligated in RHU I increased from 2 to 28 during the MGP implementation. Of 17 IUD insertions by the Well-Family Midwife Clinic, eight were subsidized by MGP funds, and out of 25 DMPA clients at the clinic, five were covered by the MGP.

Service provision. Initial data show that the activities carried out as part of the MGP have achieved only a slight increase in TT2+ coverage. With respect to family planning, however, the expanded program increased CPR significantly (Table 3 ).

Table 3. Comparison of Program Outcomes Based on FHSIS Figures, Tacloban, 1998 and 1999

\begin{tabular}{ccc}
\hline Performance Indicators & Program Outcomes (1998) & Program Outcomes (1999) \\
\hline CPR & $8 \%$ & $46 \%$ \\
TT2+ & $56 \%$ & $55 \%$ \\
VAC & $100 \%$ & $94 \%$ \\
FIC & $100 \%$ & $96 \%$ \\
\hline
\end{tabular}

Source: City Health Office

*Coverage rates go beyond $100 \%$ because denominators are estimates based on national figures.

\section{Digos, Davao del Sur}

\section{Characteristics of the Area}

Population. The municipality of Digos is located 56 kilometers from Davao City. It is situated in the northern part of Davao del Sur and serves as a crossroads for the port cities of 
General Santos, Cotabato and Davao. It is also the seat of the provincial government of Davao del Sur. Digos has become a hub of commerce and trade in the province. In 1998, the population of Digos was estimated at 112,754.

Health care delivery system. Digos is divided into two formal health jurisdictions: Rural Health Units I and II. RHU I covers 12 barangays serving a total population of 61,502. RHU II covers the remaining 14 barangays with a population of 51,252 . The local government runs 23 barangay health stations.

The municipality has two rural health physicians assigned to the RHUs, five public health nurses, 21 rural health midwives, two dentists, two dental aides, and four sanitary inspectors. Volunteer barangay health workers (BHWs) supplement these health service providers. RHU I has 199 volunteers, while RHU II has 234 barangay health workers. The Davao del Sur provincial hospital is located in Digos. Private health

The MGP team adopted a more general approach to implementing their activities, without focusing on particular programs emphasized under the MGP. facilities include a tertiary hospital, four secondary hospitals, and 15 primary local clinics.

Health budget. The health budget of Digos rose from 4.8 million pesos in 1996 to 6.5 million pesos in 1998. The amount represents about 17 percent of the municipality's total budget. Similar to the other MGP sites, a large proportion of Digos' health budget (about $90 \%$ ) is allocated for personnel services, and very little is left for drugs, equipment, repairs, outreach worker travel allowances, or other operating expenses.

\section{Planning the MGP Interventions}

Data showed TT2+ at only 52 percent in Digos in 1998. The three other indicators were relatively high before the intervention (CPR of $68 \%$, FIC of $83 \%$, and VAC of $92 \%$ ), although authorities considered them to be low. From the health providers perspectives', performance in the four areas of concern was impacted by a lack of resources for outreach work (e.g., no travel allowances, high population to worker ratio).

The MGP team in Digos adopted a more general approach to implementing their activities than the other sites, without focusing on particular programs emphasized under the MGP.

\section{Implementation of the MGP Interventions}

The Community-Based Managed and Owned Information System (CBMO). ${ }^{8}$ The $\mathrm{CBMO}$ was designed to encourage community members to feel a sense of responsibility for health-related activities. It involved the whole community, allowing them to participate in the assessment of the community's health statistics, data gathering, utilization, direct service

\footnotetext{
${ }^{8}$ The manner in which this system was developed and implemented differed from the other MGP sites' experiences. The process was heavily influenced by the technical assistance provided by the MGP field coordinator assigned to Digos.
} 
delivery, and management to ensure sustainability of health services. As it is the community that manages the system, service providers are relieved of the additional workload.

A component of the CBMO is the Bayanihan Outreach Program. This strategy was implemented in all 26 barangays. The Bayanihan Outreach Program was conceptualized to serve community members needing medical and related family planning services such as tubal ligation, IUD insertion and removal, condom and pill provision, DMPA injection, circumcision, family planning counseling, dental services, and medical consultation. This activity was the most significant MGP initiative in the area, considering the local government unit appropriated 239,000 pesos, 60 percent of its MGP funds, for the CBMO and Bayanihan Outreach Program.

Health and nutrition posts. Several health and nutrition posts in the area that were inactive for some time were reopened. The health and nutrition posts served as extensions of the main barangay health station, providing new venues for service delivery in far away areas and making information more accessible to the community. For instance, herbal medicines, which supplement the primary medicinal needs of the community, were collected and planted at the posts.

The health and nutrition posts served as extensions of the main barangay health station, providing new venues for service delivery in far away areas.

The community provided in-kind resources, working for free to help construct the health posts.

Other programs in Digos included:

- Tetanus toxoid integration in the pre-marriage counseling program. TT injections were made available for women attending pre-marriage counseling. This effort was facilitated by the close physical distance between the Women's Center (the venue for local counseling sessions) and RHU I, and was supported by an ordinance from the local government unit. Additionally, the educational component of the counseling program was enriched in several respects through MGP activities.

- Bilateral Tubal Ligations. The rural health units started providing tubal ligation services for 10 clients per month, whereas before this service was conducted at irregular schedules, leading to overcrowding. Bilateral tubal ligation was provided free of charge under the MGP. The provincial health office provided anesthetics and personnel, and the municipal health offices provided post-operation medicines and transportation.

- Outreach to small and medium enterprises. An interagency Information, Extension and Communication and family planning service delivery system was established for female workers in small and medium enterprises. This strategy aimed to reach women who work from early morning to early evening and do not 
have a chance to make use of public health services, particularly family planning services. However, progress in this activity has been slow.

\section{Highlights of MGP Implementation: Innovations and Bottlenecks}

The MGP activities in Digos highlighted a participatory process for obtaining information on clients needing services, focusing on remote barangays, and achieved an apparent increase in CPR, FIC, fully immunized mothers, and vitamin A coverage rates. These MGP interventions have been effective in reaching out to underserved and inaccessible communities, decreasing missed opportunities, and increasing availability of health services to clients.

Community volunteers are key partners in reaching out to individuals who may have unmet needs and in making service delivery more efficient. The integration of tetanus toxoid immunization into pre-marriage counseling also captures missed clients. This intervention should be sustained, but requires that service providers maintain a recording system that will enable them to monitor their clients closely.
The MGP activities in Digos highlighted a participatory process for obtaining information on clients needing services.

\section{Outputs and Coverage of Program Services}

Outputs. Through the Bayanihan Outreach Program, all barangays were visited at least once between June and December 1999. The outreach generated community interest and awareness of health programs, leading to the construction of health and nutrition posts. Additionally, 38 clients from RHU I and 56 clients from RHU II were referred for tubal ligation between June 1999 and March 2000.

Service coverage. With only a six-month observation period, there was little discernable change in the indicators. TT2+ coverage increased somewhat, but CPR, FIC and VAC coverage fell slightly (Table 4).

Table 4. Comparison of Program Outcomes Based on FHSIS Figures, Digos, 1998 and 1999.

\begin{tabular}{ccc}
\hline Performance Indicators & Program Outcomes (1998) & Program Outcomes (1999) \\
\hline CPR & $68 \%$ & $58 \%$ \\
TT2+ & $53 \%$ & $56 \%$ \\
VAC & $92 \%$ & $87 \%$ \\
FIC & $83 \%$ & $81 \%$ \\
\hline
\end{tabular}

Source: Combined RHU records 


\section{OVERALL ASSESSMENT OF THE MATCHING GRANTS PROGRAM IN THE FOUR STUDY AREAS}

\section{Planning as a New Experience}

The grant application and planning process represented a new experience for the local government grantees in that it was the first time they had taken such an active role in obtaining funding for carefully targeted interventions. They identified goals and activities, developed rationales for activities based on local conditions and needs, and determined actual allocation of the grant. For the most part, the process was participatory, involving as many local stakeholders as possible. Technical assistance, provided by the Department of Health regional office and the Management Sciences for Health field coordinator, played an important role for program implementation to proceed as planned and, relatively, without much delay. Table 5 summarizes the major steps entailed from the application process to the implementation of Matching Grants Program activities in the local government units. It is interesting to note that it took longer to complete the steps, on average, for the second batch of MGP recipients. This could be partly explained by the increasing number of applicants, which had to be processed by the Department of Health regional office. The steps that took the longest were the review of drafts, regional approvals, and the release of funds from the region.

Table 5. Critical Steps in the Implementation of the Matching Grants Program Based on the Experience of Four MGP Areas: San Jose del Monte, Dasmarinas, Tacloban and Digos, 1999

\begin{tabular}{lcc}
\hline & \multicolumn{2}{c}{ Average Number of Working Days } \\
\cline { 2 - 3 } Critical Steps & $\begin{array}{c}\text { First Batch of } \\
\text { MGP Recipients }\end{array}$ & $\begin{array}{c}\text { Second Batch of } \\
\text { MGP Recipients }\end{array}$ \\
\hline & & \\
1. Invitation letter sent - RFA received by LGU & 3 & 5 \\
2. LOI submitted to DOH regional office & 7 & 7 \\
3. First visit/orientation & 8 & 16 \\
4. First draft of proposal prepared & 9 & 14 \\
5. Review of drafts/regional approval & 9 & 25 \\
6. LGU approval of draft/final draft & 10 & 22 \\
7. MOA signed & 12 & 21 \\
8. LGU received MGP fund & 11 & 38 \\
9. First key activity implemented & 8 & 16 \\
TOTAL & $\mathbf{7 7}$ & $\mathbf{1 6 4}$ \\
\hline
\end{tabular}


Table 6: A Summary of General MGP Interventions in the Four Evaluation Areas, February 2000

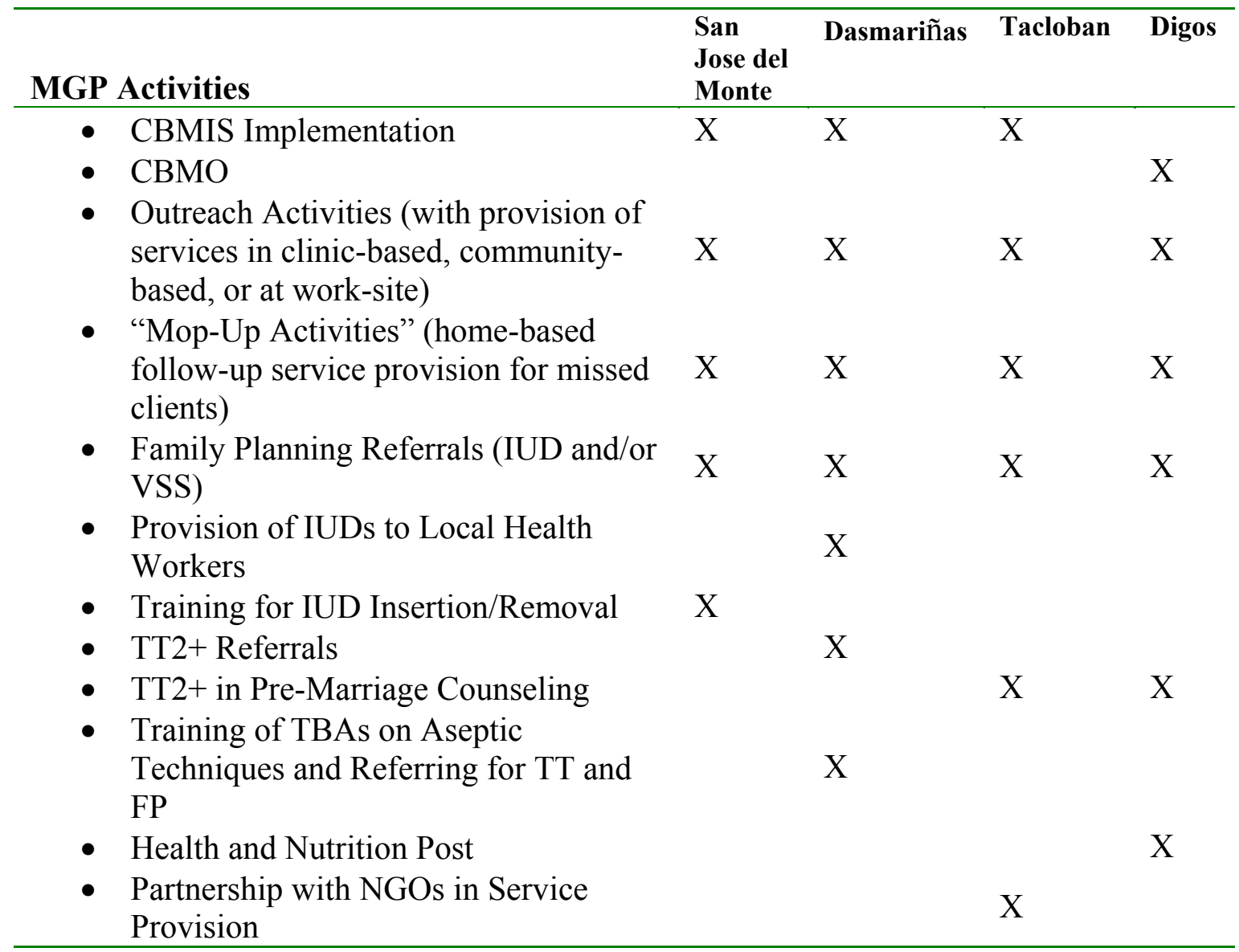

\section{Analysis of Health Problems and Choice of Interventions}

For the most part, local governments relied on FHSIS data, the only data available at the time, to analyze health problems and set targets. The limitations of the FHSIS data for estimating coverage rates of interventions are well known. Based on their assessments of where coverage rates needed significant improving, local government units chose their interventions. The types of interventions varied by site, both in terms of which of the four service areas emphasized, and in terms of specific activities used to address unmet needs and provide measurable impacts. The interventions are summarized in Table 6 (above). In most cases, the activities chosen were quite creative and innovative.

\section{Implementation of MGP Interventions}

Application of a new health information technology: The CBMIS. A major feature of the MGP in three of the four study areas was the adoption of a community-based monitoring and information system with technical assistance from Management Sciences for Health. The 
CBMIS combines information gathering with service delivery. It provides information on clients with unmet needs as determined during house-to-house (master listing) visits by barangay health worker volunteers. In introducing the CBMIS, Management Sciences for Health has drawn from the experience of a Davao operations research project that used the unmet need algorithm to identify women for family planning services. FRONTIERS Philippines staff proposed the use of the CBMIS in implementing MGP activities. In San Jose del Monte, CBMIS information is presented in the form of a Data Health Board for community use. Experiences in Tacloban and Dasmariñas were similar; master listing involved outreach health workers (with more involvement of midwives and nurses in Tacloban) and put emphasis on referrals to fixed facilities, as well as rural health unit service provision. Digos adopted a similar system called the Community-Based Managed and Owned Information System (CBMO). Unlike the CBMIS, the CBMO included community participation in the data collection and utilization process.

While the potential usefulness of the CBMIS is great, it requires sustained participation to implement on a routine basis. As the experiences of San Jose del Monte, Dasmariñas and Tacloban show, maintaining a CBMIS requires a number of trained health workers who can collect the necessary information accurately and process it in support of service delivery. The introduction of incentives for health workers in San Jose del Monte, and to some extent in Dasmariñas, may help maintain health worker participation for the task, but how long local authorities can continue the incentive system remains a question.

\section{Mobilization of New Resources for Health}

The Matching Grants Program provides up to 500,00 pesos in new resources for health. Local government resources then match the MGP funds. MGP activities may also generate additional resources, whether financial or in kind, from the Department of Health or participating NGOs. For example, in the implementation of the Family Health Days in Tacloban, the city had to rely on a number of partners. Logistical support, medicines, and supplies from the Department of Health, the Provincial Health Office, and the GLAXO drug company augmented the local government units' resource requirements. Active involvement of barangay health workers, supply point officers, and barangay nutrition scholars and the facilitative efforts of local barangay officials were crucial in community mobilization. NGOs (LEFADO and the Marie Stopes Foundation), the City Population Office, and the Leyte Institute of Technology provided strong partnerships in advocacy and service provision.

However, there are concerns that the new funds from the Matching Grants Program may not actually add to the net funding available for health programs. Local governments may actually reduce their health budgets by the amount of funding received through the MGP. Additionally, local governments may simply shift resources away from other health programs to match the MGP funds.

There is not enough data to determine if local health budgets were actually reduced because of MGP funds. The health budgets in the four sites increased in absolute terms from 1998 to 1999, although the percentage of the total budget allocated to health declined somewhat in all of the areas. In San Jose del Monte the health budget as a percentage of the total budget declined from 4.4 percent in 1998 to 4.2 percent in 1999. In Dasmariñas it dropped from 7.1 
percent to 6.9 percent, in Tacloban from 4.8 percent to 3.0 percent, and in Digos from 17.6 percent to 15.4 percent.

Data on the actual amount of matching funds provided by the local government are not available in all of the study areas, although all of them did provide both funding and staff time to implement the MGP activities. In Dasmariñas, the local government provided a total of 117,900 pesos to match the 400,000 pesos provided by the MGP. However, much of this money was realigned from funding already budgeted in 1999 for other purposes. Hence, in Dasmariñas MGP activities have displaced funds for other activities whose performance may possibly suffer from reduced funding.

The Department of Health Provincial Health Office also provided resources, mostly in kind, including vaccines and syringes in Dasmariñas and Tacloban. In of San Jose del Monte and Digos the communities also provided in-kind resources in terms of volunteer work, and Tacloban tapped NGOs. It is not clear, however, whether these resources would have been provided to the local governments for similar activities and are therefore not unique to MGP interventions.

It is important to note that all of the local government health budgets in the study area are spent mainly on personnel salaries and benefits (about 80\%), leaving little for operations and supplies including drugs, equipment, repairs, and travel allowances for outreach and supervision activities. The MGP funds can be viewed as providing resources to improve operations because these funds were spent directly on interventions to improve the capacity of the local health sector to provide critical program interventions.

\section{Expansion of Services in the Four Program Areas}

The MGP led to the implementation of activities focused on improving coverage of key services according to the individual needs of each study area. It is still too early to determine which interventions had the most impact. Additionally, studies should be done to see which interventions were most cost-effective. For example, that community outreach activities conducted in San Jose del Monte and Tacloban required a lot of preparation and input to mount. While such outreach activities do reach a number of clients, it is not clear whether these clients would have used routine services if the outreach activities were not available. In other words, the net increase in clients seen may be smaller than the number of clients reached through outreach activities, as these activities may be incorporating clients who would seek out routine services anyway.

\section{Innovations in Service Delivery}

In San Jose del Monte, Bulacan, an incentive system attracted volunteers for labor-intensive activities like the CBMIS. The CBMIS, together with the call slips, gave the rural health unit a system for prioritizing service provision. The MGP there also served as a catalyst for other health programs, such as environmental sanitation. 
Dasmariñas adopted a three-pronged approach to improve TT2+ coverage. Through the barangay health station Expanded Program on Immunization, home visits to follow up TT2+ defaulters, and industrial site visits to provide services to working and highly mobile women, they were able to improve their coverage rates.

Tacloban added family planning and TT2+ services to its existing social hygiene clinic services and pre-marital counseling program. It also tapped NGO resources to expand its service delivery network.

Digos also added TT2+ services to its pre-marriage counseling program.

\section{Results}

Performance in the four study areas with respect to improving coverage of key services is mixed. In San Jose del Monte, FIC, VAC and TT2+ coverage rates were maintained at their previously high levels, and CPR doubled compared to the baseline, based on FHSIS reports.

In Dasmariñas' RHU I performance improved dramatically for TT2+ and remained the same for CPR. But RHU I had a drastic reduction in FIC and VAC performance. While RHU II's FIC rate remained about the same, TT2 + and CPR rates markedly improved, and VAC performance declined drastically. These results suggest that efforts to focus on one outcome may displace resources from other programs that are doing relatively well.

In Tacloban City, Leyte, initial data show some progress in increasing TT2+ coverage based on identified targets. With respect to family planning, the expanded program under the MGP reduced the percent of married women of reproductive age with unmet needs to 81.4 percent.

In Digos, Davao del Sur there was little change that could be discerned in the indicators during the six-month observation period. TT2+ coverage increased somewhat, but CPR, FIC and VAC fell slightly.

\section{UTILIZATION OF STUDY FINDINGS}

Disseminating the results of this study, efforts have focused on the major stakeholders in the Matching Grants Program including the Department of Health (local and national levels), local government units, Management Sciences for Health, and USAID.

Throughout the project, feedback was regularly exchanged in the field between the MGP field coordinators (or regional technical advisors) and the Population Council field evaluators. In addition to on-site feedback, FRONTIERS staff presented initial findings to MGP stakeholders midstream. Presentations and briefings were held at the Population Council office and at a MGP local government summit in Bacolod City. Findings were also presented during a regular CA meeting at USAID. In a recent interview with Management 
Sciences for Health project management staff, ${ }^{9}$ they cited specific examples of results disseminated through the FRONTIERS MGP evaluation study being utilized for program management including:

- The MGP requirement that grantees have a minimum population of 100,000 was reduced to 80,000 . In addition to targeting municipalities or cities, the MGP has initiated a "clustering" strategy where projects can take place in several small municipalities clustered together, so as to expand the MGP to areas that may not be able to meet the population requirement. This new policy was adopted in response to the evaluation report suggestion that there is tension between the goal of demonstrating impact and the objective of equity in health provision. The MGP has specified that programs target hardto-reach communities within the municipalities in order to provide services in areas that are geographically disadvantaged and underserved through existing health services.

- The MGP has become more specific in terms of what must constitute the local government's match. Previously, the term "match" was liberally construed by the local governments, resulting in unevenness across MGP areas in terms of funds and in-kind resources provided by local units. In the next rounds of MGP grants, the grantee must allocate an amount equal to 25 percent of the MGP grant, from a new source of budgetary funding. In addition, the MGP funds are to be used first to improve facilities to meet the requirements of "Sentrong Sigla," and second to enroll indigents in the Indigent Program of the Philippine Health Insurance Corporation.

- The process of distributing funds has been simplified. Local governments no longer have to submit MGP plans as a condition of fund release. Once they have indicated to the Department of Health that they are interested in using their MGP funds, representatives from the Department will then provide an orientation. Upon completion of the orientation, the interested local government will then be required to sign a Memorandum of Agreement with the Department, which will allow the immediate access to 40 percent of their MGP funds. This initial money must be used to initiate the CBMIS through training of local health workers, data collection, and processing that will then form the basis of MGP program planning in the area. Upon the submission of the MGP program plan to the Department of Health, the remaining 60 percent of the grant will be released to the local government unit. These changes were made based on the evaluation report's review of length of time that it takes to complete the steps in program implementation (see Table 5).

- As mentioned earlier, the CBMIS has become a central component of the MGP. As an information gathering instrument and as a strategy for service provision, the CBMIS is now considered the "heart and soul" of the MGP (according to a Management Sciences for Health representative). In addition to introducing the CBMIS as a component of the MGP, several improvements in the administration of the CBMIS were made. For instance, a referral system has been built in. Upon completion of a survey, community

\footnotetext{
${ }^{9}$ In a meeting held on May 25, 2001 Dr. Sonny Magboo of the Management Sciences for Health enumerated the areas where the evaluation project results have been utilized to improve and sharpen MGP implementation in subsequent MGP sites.
} 
members will be given a health card containing information on their health status and providing them referrals to the appropriate health facilities for follow-up care. As a strategy of consolidating CBMIS data, "spot-mapping" has been introduced to identify key areas of need. Additionally, barangay captains are being encouraged to become more active stakeholders, as they are important in mobilizing both barangay health workers and community members. Finally, the CBMIS is being designed to specifically address the needs each different program area.

\section{CONCLUSIONS AND RECOMMENDATIONS}

Based on the evaluation of four Matching Grants Program sites, it is clear that the program has had an impact on the roles played by key stakeholders as a strategy for the provision of health services, particularly in the areas of FIC, CPR, VAC and TT2+.

\section{Stakeholders' Roles under MGP}

Department of Health Regional Office: The Department of Health Regional Office plays a significant role in the application process, identifying local government units to invite into the program, providing orientation to interested LGUs, helping to draft initial MGP plans, approving the plans, and finally, disbursing the MGP funds. Upon approval of the MGP plan and fund disbursement, the Department of Health provides other in-kind resources including training on the CBMIS, monitoring of program implementation, and, in some cases, provision of medical supplies.

Management Sciences for Health: At this initial stage of the MGP, the Department of Health's regional office lacks the capacity, especially in terms of personnel, to provide local governments with the needed technical assistance. Hence, MSH provides technical assistance to LGUs, assigning a regional technical advisor (RTA) to MGP areas. The RTA provides support in initial planning and in program implementation.

Provincial Health Office: Based on observations of the four sites evaluation here, the provincial health office has played much less of a role than has the regional office. Indeed, there is uncertainty about the role it should play in the MGP. It is recommended that the PHO's specific role in the MGP be examined and appropriate policy changes be made to better include them in MGP. Further, the capacity of this office must be built to enable it to better take on the responsibility for technical assistance. For instance, in the case that the LGU approaches the regional office for supplies, they are first disbursed to the PHO, which then has the responsibility of distributing them. This arrangement can lead to serious problems if coordination among the various units is not enhanced.

Local Government Units: The LGUs adopted different strategies across the four evaluation sites in terms of assigning MGP point-people. In one site, one doctor from the two RHUs took the lead as the MGP point-person. Her leadership had a positive impact on the kinds of outputs produced by the program there. In another site, the mayor assigned responsibility for the MGP to the city health office where it was delegated to the family planning coordinator, a nurse. Delegating responsibility for the MGP from one person to another may explain why 
there were critical lapses in implementation in this area. In other cases, each of the doctors in the RHUs covered by the MGP were responsible for administering and implementing the MGP. Reports from the field indicate, however, that this arrangement can be problematic as doctors sometimes compete for resources, which has consequences for community members seeking health services. It is recommended that a "policy-champion" be identified within each LGU to be an advocate for MGP implementation.

Midwives/nurses and local health workers (both trained and volunteer): Local barangay health workers, nurses, and midwives were involved in all stages of the MGP process, from planning and implementation to evaluation. In other words, the MGP has been a highly participatory process. However, the degree and manner in which these actors participated differs from area to area. Local government units should consider effective ways to sustain barangay health worker involvement through incentive systems, in view of their voluntary yet critical role in CBMIS implementation.

Added responsibilities were placed on the shoulders of nurses and midwives. In one area they took a lead role in CBMIS implementation. One recommendation that stems from this experience is that the roles and functions of these health workers must be clearly specified, especially with respect to the tasks of updating the master list and collating and analyzing the CBMIS data.

However, the use of volunteers was not always a uniformly positive experience in the areas that were evaluated. Given the critical role of outreach workers in the program, there is a need to provide these workers with appropriate training and motivation.

Barangay officials: From experiences in the evaluation sites, links with local barangay officials are important for the MGP. The barangay officials mobilize their constituents and provide in-kind resources, including securing venues for outreach activities, supplies and food.

NGOs and private sector: The MGP has helped to create partnerships among local government units, NGOs and the private sector. The NGOs and private sector institutions have been important in maximizing MGP activities through service support and in-kind support. Several industries not only provided the MGP with supplies, but also allowed MGP staff to provide on-site services to their workers.

\section{Lessons Learned}

Documenting the performance of Matching Grants Program recipients provides a number of lessons for local governments planning and implementing focused interventions to achieve specific health objectives and for Department of Health personnel designing programs to support local governments.

Planning and implementing specific interventions was a new experience for the local government units. With technical assistance from the Department of Health and regional technical assistants, they identified specific demand and service delivery problems in the four 
program areas, and designed focused interventions to address these problems. The facilitative and participatory approach of the MGP allowed this process to emerge. Local health authorities were able, in most instances, to focus services on areas and groups that needed them the most, given limited resources.

For the most part, local government units relied on FHSIS data to analyze problems and set targets. The limitations of the FHSIS data for planning are well known, but they were a useful starting point. New information was gathered at the outset of the projects to determine areas of unmet need for potential clients. The CBMIS technology, refined earlier in an operations research study on improving quality of care in family planning, was used to identify unmet need in this program in three of the four sites evaluated.

The CBMIS was quite useful in identifying potential clients with unmet needs for family planning. However the CBMIS requires a lot preparation and sustained activity to implement on a routine basis. The system still needs further refinement, particularly in terms of the referral system and ensuring that it is updated regularly. It requires a number of health workers to gather data through house-to-house visits and subsequently process the data to support service delivery efforts.

The MGP experience indicates that, in addition to the MGP funds and the local match, local governments were able to mobilize other resources, whether financial or in kind, from various sources to implement their interventions. Sources included Department of Health regional and provincial offices, NGOs, and private drug companies. There is a question, however, as to whether money from the MGP really represented a net addition to local governments' resources for health, or whether local governments' simply displaced funds for other important health programs (such as malaria, or TB) to provide the match. Data obtained from the local governments regarding their budgets and allocations, including allocations within the health sector, were not adequate to provide definite answers to this question.

In conclusion, while questions of sustainability and cost-effectiveness remain, this evaluation uncovered a number of important findings to guide future MGP implementation. Local governments are responsive to new ideas (e.g., adoption of new information technology such as the CBMIS). MGP interventions are innovative (e.g., use of incentives to attract volunteers in labor-intensive activities like the CBMIS, or adopting a multi-pronged approach to deliver services to difficult to reach mobile population in industrial areas). Initial data indicate that services are being provided to priority clients in each of the four sites that evaluators monitored. There are indications that local government units have identified mechanisms for outsourcing and mobilizing other community resources for this program, including the support of NGOs and other private sectors. 